Please do not remove this page

RMIT

UNIVERSITY

\title{
RF magnetron sputtered perovskite-oriented PSZT thin films on gold for piezoelectric and ferroelectric transducers
}

Bhaskaran, Madhu; Sriram, Sharath; Holland, Anthony

https://researchrepository.rmit.edu.au/esploro/outputs/9921859809101341/filesAndLinks?institution=61RMIT_INST\&index=null

Bhaskaran, M., Sriram, S., \& Holland, A. (2006). RF magnetron sputtered perovskite-oriented PSZT thin films on gold for piezoelectric and ferroelectric transducers. Electronics Letters, 42(4), 244-245.

https://doi.org/10.1049/el:20063422

Published Version: https://doi.org/10.1049/el:20063422

Repository homepage: https://researchrepository.rmit.edu.au

(c) IEE 2006. Personal use of this material is permitted. However, permission to reprint/republish this material for advertising or promotional purposes or for creating new collective works for resale or redistribution to servers or lists, or to reuse any copyrighted component of this work in other works must be obtained from the IEEE.

Downloaded On 2023/04/26 20:18:44 +1000 


\section{RF magnetron sputtered perovskite-oriented PSZT thin films on gold for piezoelectric and ferroelectric transducers}

\author{
M. Bhaskaran, S. Sriram and A.S. Holland
}

Conditions for depositing perovskite-oriented $\mathrm{Pb}_{0.92} \mathrm{Sr}_{0.08}\left(\mathrm{Zr}_{0.65} \mathrm{Ti}_{0.35}\right)$ $\mathrm{O}_{3}$ thin films on gold by RF magnetron sputtering are investigated. Deposition results were analysed by scanning electron microscopy, $\mathrm{X}$-ray photoelectron spectroscopy and X-ray diffractometry. It was found that the desired perovskite phase can be obtained at a substrate temperature of $300^{\circ} \mathrm{C}$, much lower than the typically reported $650^{\circ} \mathrm{C}$ for deposition on platinum.

Introduction: Doped lead zirconate titanate (PZT) compounds are used in various applications owing to the wide spectrum of properties exhibited. Lead zirconate titanate and lanthanum-doped lead zirconate titanate (PLZT) deposition techniques and properties are widely reported in published literature. Strontium-doped lead zirconate titanate (PSZT) is noted for its piezoelectric and ferroelectric properties [1] (higher than PZT and PLZT), but deposition techniques to obtain high quality perovskite oriented thin films are not widely reported.

PZT and PLZT thin-film deposition by RF magnetron sputtering is conventionally carried out on platinum and at high substrate temperatures of 600 to $700^{\circ} \mathrm{C}[2,3]$. This Letter reports an alternative choice of substrate metal coating and sputtering substrate temperature to obtain the perovskite phase. Analysis of the films obtained was carried out by scanning electron microscopy (SEM), X-ray photoelectron spectroscopy (XPS) and X-ray diffractometry (XRD).

Thin-film deposition: RF magnetron sputtering was carried out with a $100 \mathrm{~mm}$ diameter $8 / 65 / 35$ strontium-doped lead zirconate titanate target, using the conditions in Table 1 . The system operates at a frequency of $13.56 \mathrm{MHz}$ and the magnetron is made of a permanent magnet array (Gencoa Ltd., UK). Tuning of the inductive and capacitive load resulted in a forward power of $100 \mathrm{~W}$ and a reflected power of $\sim 1 \mathrm{~W}$, indicative of a power of $99 \mathrm{~W}$ between the electrodes.

Table 1: RF magnetron sputtering conditions

\begin{tabular}{|c|c|}
\hline Target & PSZT $(8 / 65 / 35)$ \\
\hline Target diameter & $100 \mathrm{~mm}$ \\
\hline RF power & $100 \mathrm{~W}$ \\
\hline Substrate temperature & $300^{\circ} \mathrm{C}$ \\
\hline Target to substrate distance & $70 \mathrm{~mm}$ \\
\hline Gas mixture & $\mathrm{Ar}_{2}(9: 1)$ \\
\hline Base pressure & $1.0 \times 10^{-5}$ Torr \\
\hline Sputtering pressure & $1.0 \times 10^{-2}$ Torr \\
\hline Sputtering duration & $4 \mathrm{~h}$ \\
\hline
\end{tabular}

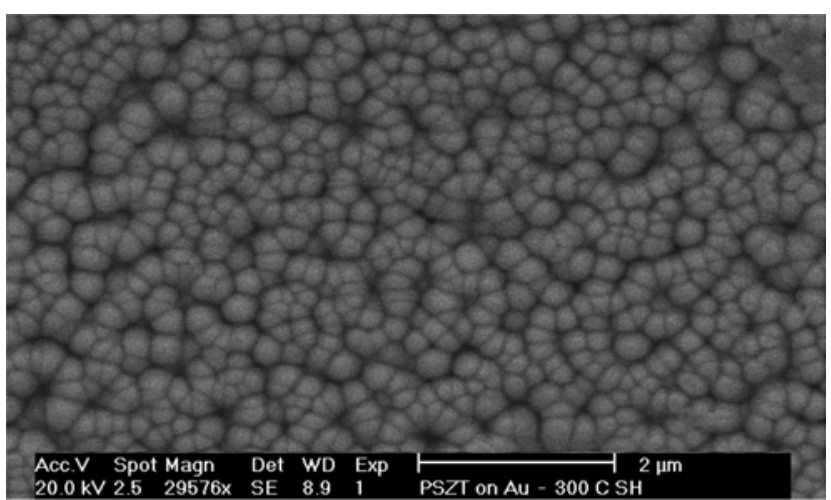

Fig. 1 Scanning electron micrographs of deposited PSZT thin film using conditions given in Table 1

Deposition was carried out on a silicon substrate with $15 \mathrm{~nm}$ of titanium covered by $150 \mathrm{~nm}$ of gold; both deposited by electron-beam evaporation.
Results: A film thickness of $1.8 \mu \mathrm{m}$ was obtained by sputter deposition for $4 \mathrm{~h}$. Fig. 1 shows a SEM micrograph obtained for a PSZT film deposited on gold with substrate heating of $300^{\circ} \mathrm{C}$. The system used was a Philips XL30 scanning electron microscope. The grains were closely packed, have an average diameter of approximately $300 \mathrm{~nm}$, and the crack-free film has a surface roughness of $29 \mathrm{~nm}$.

The composition of the deposited film was verified by X-ray photoelectron spectroscopy (XPS) using a VG Instruments Model 310 Auger/XPS spectrometer. Expected peaks for lead, zirconium, titanium, and oxygen were observed, as shown in Fig. 2. Peaks for the dopant (strontium) were not pronounced owing to its low concentration, and detected peaks could not be resolved satisfactorily owing to their vicinity to the peaks of lead.
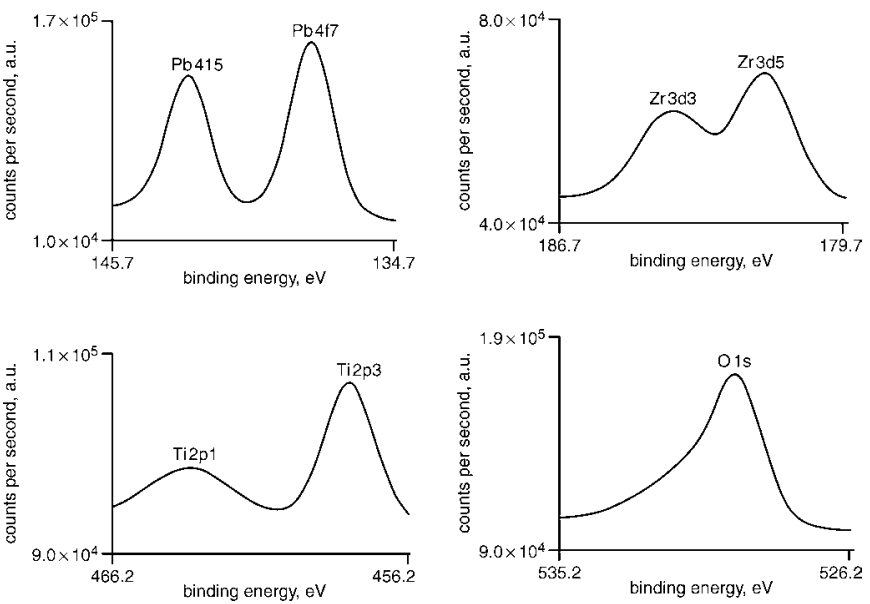

Fig. 2 X-ray photoelectron spectroscopy peaks observed for major elements of PSZT in deposited thin film - lead $(\mathrm{Pb})$, zirconium $(\mathrm{Zr})$, titanium (Ti), and oxygen $(O)$

XRD analysis was carried out using a Bruker D8 DISCOVER system, with a $\mathrm{Cu} \mathrm{K} \alpha$ source (wavelength $0.154 \mathrm{~nm}$ ). The $2 \theta$ sweep range was $20^{\circ}$ to $60^{\circ}$, with a step size of $0.02^{\circ}$. The XRD results in Fig. 3 show the existence of a strong (111) perovskite orientation peak at a $2 \theta$ value of $38.52^{\circ}$. This implies a lattice spacing of $0.40448 \mathrm{~nm}$ [4]. The International Centre for Diffraction Data (ICDD) Card No. 33-0784 [5] for PZT was used as the reference standard.

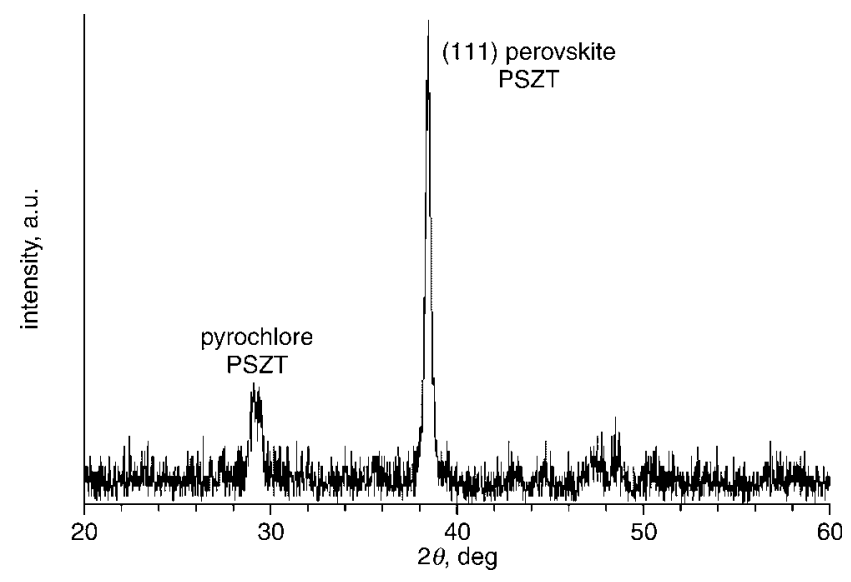

Fig. 3 X-ray diffraction result for deposited PSZT thin film using conditions given in Table 1

Discussion: SEM micrographs and XRD results show that the deposited films are well oriented in the perovskite phase. The XRD peak at $38.52^{\circ}$ compares well with the $38.25^{\circ}$ (111) peak listed in the ICDD (JCPDS) Card. This difference can be explained by the following factors: (i) the presence of strontium $(1.6 \%)$ as a dopant in PSZT, while the standard is for undoped PZT; (ii) the fact that the standard is for powders and not thin films; and (iii) the existence of stress in the deposited film. 
In comparison with other films that we deposited and other reported work on perovskite oriented thin films, we can report three improvements in the sputtering of perovskite PSZT:

1) The deposition is performed at a substrate temperature of $300^{\circ} \mathrm{C}$ which is much lower than the standard $650-700^{\circ} \mathrm{C}$.

2) The deposition is on gold and not platinum. This is an advantage in terms of cost. Moreover, gold is easier to pattern and etch than platinum, and such films can be better incorporated in devices.

3) Literature [6] reports the presence of cracks in sputtered films thicker than $1.2 \mu \mathrm{m}$ for films without a sol-gel based seed layer, while under the conditions reported in this Letter the sputtered film was crack-free for a thickness of $1.8 \mu \mathrm{m}$.

Conclusion: This Letter discusses conditions by which (111) perovskite oriented films were deposited on $150 \mathrm{~nm}$ of electron-beam evaporated gold on titanium and silicon. The results have been verified with SEM micrographs, XPS spectra, and XRD diffractograms, using existing literature and ICDD (JCPDS) Card No. 33-0784. This deposition has been carried out at a lower than conventional temperature of $300^{\circ} \mathrm{C}$ and on gold, a cheaper and easier-to-use material than platinum.

(C) IEE 2006

11 October 2005
M. Bhaskaran, S. Sriram and A.S. Holland (Microelectronics and Materials Technology Centre, School of Electrical and Computer Engineering, RMIT University, GPO Box 2476V, Melbourne, Victoria 3001, Australia)

E-mail: madhu.bhaskaran@gmail.com

\section{References}

1 Zheng, H., Reaney, I.M., Lee, W.E., Jones, N., and Thomas, H.: 'Surface decomposition of strontium-doped soft $\mathrm{PbZrO}_{3}-\mathrm{PbTiO}_{3}$ ', J. Am. Ceram. Soc., 2002, 85, pp. 207-212

2 Kim, T.S., Kim, D.J., and Jung, H.J.: ' $\mathrm{N}_{2} \mathrm{O}$ reactive gas effect on RF magnetron sputtered $\mathrm{Pb}\left(\mathrm{Zr}_{0.52} \mathrm{Ti}_{0.48}\right) \mathrm{O}_{3}$ thin films', J. Appl. Phys., 1999, 86, pp. 7024-7028

3 Holland, A.S., Kandasamy, S., Fardin, E., Mitchell, A., and McCulloch, D.: 'Formation of lead lanthanum zirconate titanate films by heat treatments'. COMMAD, Brisbane, Australia, 2004

4 Suryanarayan, C., and Norton, M.G.: 'X-ray diffraction: a practical approach' (Plenum Press, New York, 1998)

5 Powder Diffraction Pattern File (PDF), JCPDS-ICCD, Swarthmore, PA 19081, USA

6 Park, C.-S., Kim, S.-W., Park, G.-T., Choi, J.-J., and Kim, H.-E.: 'Orientation control of lead zirconate titanate film by combination of sol-gel and sputtering deposition', J. Mater. Res., 2005, 20, pp. 243-246

Electronics Letters online no: 20063422

doi: 10.1049/el:20063422 